Migräne

\title{
44 neue Genvarianten entdeckt
}

— In der bisher weltweit umfangreichsten Migränestudie wurden 44 neue Genvarianten entdeckt, die mit einem erhöhten Risiko verbunden sind, an Migräne zu erkranken. Das teilt die Schmerzklinik Kiel mit. Zahlreiche dieser Genvarianten sind in den Berei- chen des Erbguts lokalisiert, die das Blutkreislaufsystem des Gehirns regulieren [Nat Genet 2016; 48(8):856-66]. Die neuen Entdeckungen weisen darauf hin, dass eine Störung der Blutversorgung des Gehirns wesentlich für die Entstehung der Migräne ist.

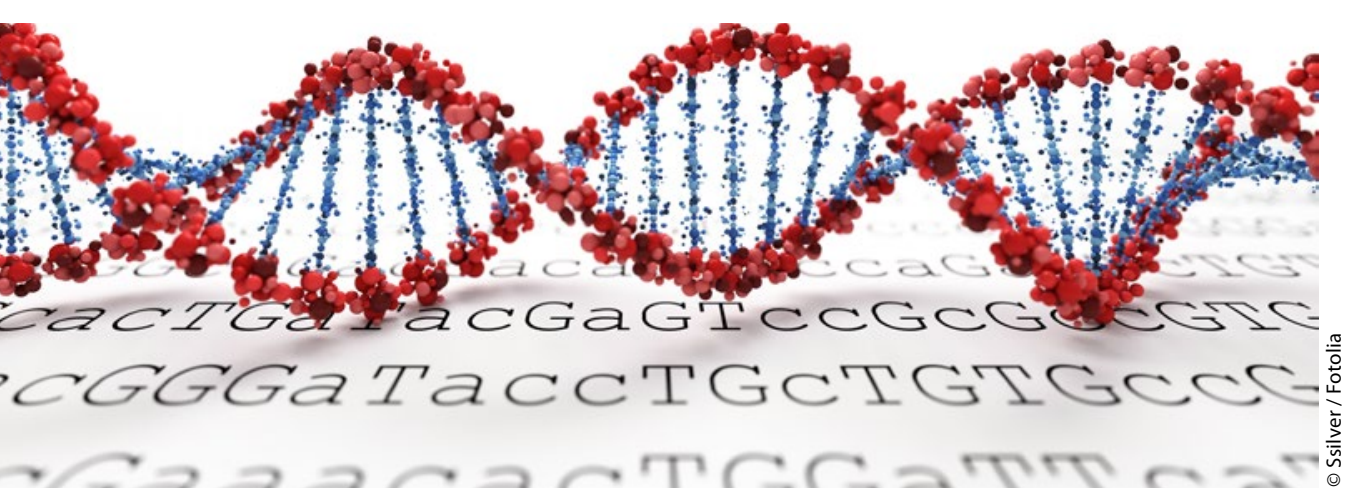

Das Projekt wurde über mehrere Jahre hinweg von Wissenschaftlern des internationalen Kopfschmerz-Gen-Konsortiums unter Beteiligung von Forschern der Schmerzklinik Kiel durchgeführt. Mitgearbeitet haben auch Forscherteams aus Australien, Dänemark, Estland, Finnland, Deutschland, Island, Niederlande, Norwegen, Spanien, Schweden, des UK und den USA. Die Studie basiert auf Erbgutproben von 375.000 Menschen.

„Die Daten unserer Studie belegen erstmals, dass die Reaktionsweise der Arterien und der glatten Muskulatur in den Gefäßwänden des Blutkreislaufsystems wesentlich für die Migräneentstehung ist" wird Professor Hartmut Göbel, Direktor der Schmerzklinik Kiel und Koautor in einer Mitteilung der Klinik zitiert. Eine zeitweise Störung der Gehirnversorgung verursacht durch die besondere genetische Ausstattung der Betroffenen nehme nach den neuen Daten eine entscheidende Rolle in der Auslösung von Migräneattacken ein.

(eb)

Antikörpertherapie bei Migräne

„Wir stehen vor einer Revolution“

— In Kürze bestehe die Chance, den Patienten statt eines "zusammengewürfelten Haufens" von wenig wirksamen und nebenwirkungsstarken Prophylaktika eine Migräne-spezifische Behandlung anzubieten, sagte Professor Peter Goadsby vom King's College im Juni in London beim europäischen Neurologenkongress in Kopenhagen. "Wir stehen vor einer Revolution", sagte Goadsby, der an der klinischen Entwicklung der CGRP-Antagonisten beteiligt war.

Inzwischen sind vier humanisierte monoklonale Antikörper gegen das "Calcitonin gene-related peptide" (CGRP) in der fortgeschrittenen klinischen Entwicklung. Sie werden meist alle zwei bis vier Wochen subkutan verabreicht. Damit ließen sich in Studien bei Patienten mit episodischer und chronischer Migräne Ansprechraten von $50 \%$ bis $70 \%$ erzielen, die Zahl der monatlichen Kopfschmerztage ging um zwei bis drei Tage stärker zurück als in den Placebogruppen (von sechs auf drei bis vier). Als Nebenwirkungen traten in den Studien Reizungen an den Injektionsstellen auf, unerwünschte systemische Effekte wurden nicht häufiger beobachtet als unter Placebo. Noch immer nicht ganz geklärt ist die Wirkweise der CGRP-Antagonisten. CGRP ist im Nervensystem recht weit verbreitet und

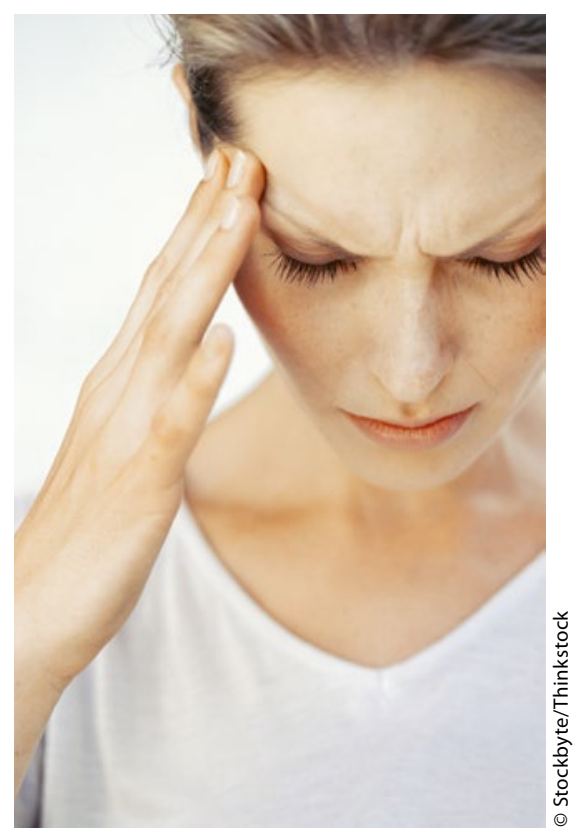

von großer Bedeutung bei der trigeminalen Schmerzübertragung. Professor Julio Pascual von der Universität Santander, Spanien wies jedoch darauf hin, dass ein großer Teil der Migränepatienten nicht von den neuen Medikamenten profitiert. Möglicherweise seien bei ihnen andere Neurotransmitter wie Glutamat oder vasoaktives intestinales Peptid (VIP) relevanter.

Diese Patienten benötigten wohl eine andere Therapie. Möglicherweise könnten Biomarker wie CGRP- oder VIP-Serumspiegel künftig diejenigen Patienten herausfiltern, die von der Behandlung am ehesten profitieren.

Mit den bisher verfügbaren Methoden lässt sich jedoch nicht exakt feststellen, wo die Antikörper ihre Wirksamkeit entfalten. Generell werde zwar davon ausgegangen, dass therapeutische Antikörper nicht die Bluthirnschranke überwinden, allerdings seien aktive Transportprozesse bekannt, die durchaus sehr große Proteine ins Gehirn schleusen können, erläuterte Professor Gitte Moos Knudsen von der Universität in Kopenhagen. Zudem gebe es Hinweise, wonach die Bluthirnschranke bei Migräneattacken durchlässiger werde. Eine zentral wirksame Komponente der CGRP-Antikörper wäre also durchaus möglich. 